\title{
Inhalt
}

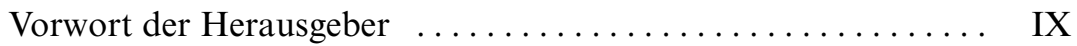

\section{Banise-Rezeption in Deutschland}

Michael Maul

Banise auf der Opernbühne. Chronologie, Autorschaft und musikalische Einblicke ...........................

Bernhard Jahn

Eine Poetik in Romanform: Colombinis Die Lybische Talestris (1715) nach Heinrich Anshelm von Ziglers gleichnamigem

Libretto

Irmgard Scheitler

Die Metamorphosen des Heraclius . .

Bärbel Rudin

Banise als Haupt- und Staatsaktion. Zum erfolgreichsten

Lückenbüßer der deutschen Verspätung im Drama ...

Christopher Meid

Klassizistische Tugenddidaxe. Friedrich Melchior Grimms

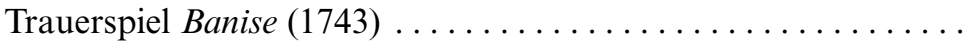

Karin Vorderstemann

»Fleuch hin, du kleiner Brief ...«. Drei unbekannte

Banise-Gedichte aus den Sammelbänden der

Görlitzer Poetischen Gesellschaft

Karin Vorderstemann

Thema und Variation. Johann Georg Hamanns

Fortsetzung der Asiatischen Banise oder des blutigen

und muthigen Pegu Zweyter Theil .. 
Nicolas Detering

»Wider die Regeln eines wahrhafften Romans«?

Die Bewertung der Asiatischen Banise in poetologischen Schriften der Frühaufklärung $(1700-1750) \quad \ldots \ldots \ldots \ldots \ldots \ldots \ldots \ldots . \ldots \ldots$

Dieter Martin

»Es lebe die asiatische Banise!« Zur intertextuellen Rezeption von Ziglers Roman in Spätaufklärung und Romantik

\section{Banise-Rezeption in Schweden}

Anna Katharina Richter

Melusinas Verwandlungen. Historienbücher als Vorläufer des

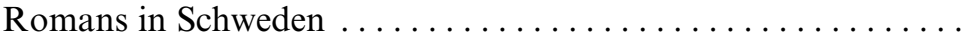

Juliane Egerer / Joachim Grage

Asiatiska Banise - Übersetzungen, Ausgaben und Rezeption der Banise-Romane in Schweden. Mit einem Ausblick auf den ersten schwedischen Originalroman ............................

Juliane Egerer

Die schwedischen Banise-Lieder: Übersetzung,

Melodiegrundlagen und Rezeptionszeugnisse .

Juliane Egerer

Wahrheit im neuen Gewand: Rolofs Händelser als Banise-Rezeption?

\section{Banise-Rezeption in Russland}

Elisabeth Cheauré / Verena Krüger

Zum Transfer eines deutschen Erfolgsromans: Die Asiatische Banise in Russland. Kulturelles Feld und Übersetzungsstrategien (am Beispiel der Diskurse um Liebe und Exotik) ............

Aleksandr L'vovič Lifšic

Die Asiatische Banise in russischer Sprache. Zur Suche nach dem

Übersetzer ... . . . . . . . . . . . . . . . . . . . . . . . . . . . . . .

Natal'ja Adol'fovna Kobjak

Die Idiomatik in Ziglers Roman Die Asiatische Banise.

Zur Methode der Übersetzung ins Russische . . . . . . . . . . . . . . 
4. Banise in den Niederlanden und in Frankreich

Lia van Gemert

Ein niederländischer Mantel für die Asiatische Banise ...

Ursula Menne

Constance récompensée. Die französische Bearbeitung der Asiatischen Banise (1771)

\section{Anhang}

Dieter Martin / Karin Vorderstemann

Bibliographie zur Rezeptionsgeschichte der Asiatischen Banise .. 483

Register ................................. 529 
